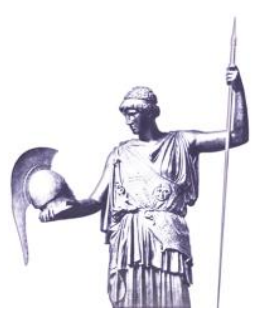

Connections: The Quarterly Journal

ISSN 1812-1098, e-ISSN 1812-2973

Рецензированная статья

Насиров и Искандаров,

Connections QJ 16, № 4 (2017): 100-112

https://doi.org/10.11610/Connections.rus.16.4.05

\title{
Перспективы Азербайджана на улучшение военной оперативной совместимости с НАТО
}

\section{Эльман Насиров и Хаяль Искандаров}

Институт политических исследований Академии публичной администрации при президенте Азербайджана

Резюме: После окончания Холодной войны НАТО осознало важность расширения своего влияние далеко за его традиционными границами для обеспечения мира и стабильности всей Европы. На передний план вышло присоединение новых членов Альянса. В свете этого подхода, сотрудничество с государствами партнерами стало важной сферой для дискуссий. Гарантирование того, что силы партнеров смогут эффективно работать вместе, стало одной из главных задач и это, в свою очередь, снова привлекло внимание к понятию «оперативная совместимость». Поэтому, в этой работе рассматривается эволюция оперативной совместимости между НАТО и странами-партнерами после окончания Холодной войны, подчеркивается значение оперативной совместимости, вводятся уровни оперативной совместимости и анализируется выполнимость оперативной совместимости на этих уровнях для Азербайджана. Исследуются разные инструменты и механизмы, задействованные Альянсом в течение последних десятилетий, и предлагаются полезные рекомендации для улучшения военной оперативной совместимости Азербайджана с НАТО. Описаны разные успешные модели оперативной совместимости в качестве примеров, которым может следовать Азербайджан.

Ключевые слова: оперативная совместимость, НАТО, безопасность, сотрудничество, подготовка, учения. 


\section{Введение}

Приняв новую Стратегическую концепцию в 1991 году, НАТО начало сосредотачивать свое внимание на развитие многонационального проецирования сил для того, чтобы адаптироваться к реалиям после Холодной войны и расширить свои способности для проведения операций по менеджменту кризисов. Стремясь реализовать свои будущие стратегические цели, НАТО надо было расширить и углубить сотрудничество со странами, расположенными за его традиционными пределами. Поэтому Альянсу срочно понадобились партнеры, которые могли быть на уровне требований НАТО. Такой подход, в свою очередь, требовал, чтобы члены Альянса, а также силы партнеров, могли бы работать вместе при проведении операций вне их территории. Первой инициативой, направленной на стимулирование совместной работы этих государств, стала программа Партнерство ради мира (ПрМ), которая была задействована в 1994 году. Конечной целью этой программы была, и все еще является, поддержка усилий партнеров по реформированию их структур национальной обороны и оказанию им помощи в развитии их национальных способностей. Если государства-партнеры, подписавшие рамку этой программы, хотели, чтобы их вооруженные силы действовали совместно, им было необходимо следовать процедурам, определенных главным образом в Брюсселе союзниками по НАТО.

Эта инициатива оказалась очень успешным инструментом. Молодая Республика Азербайджан была среди стран, которые присоединились к этой программе с надеждой в конечном итоге интегрироваться в Альянс. Вскоре после этого Альянс задействовал Процесс планирования и обзора партнерства с целью содействовать развитию сил и способностей партнеров, которые наилучшим образом могли бы сотрудничать с членами НАТО в операциях в ответ на кризисы и в других деятельностях по обеспечению безопасности и стабильности. Это обеспечило использование структурированного подхода к улучшению оперативной совместимости и к развитию способностей сил партнеров, которые могли предоставляться Альянсу для многонациональной подготовки, многонациональных учений и многонациональных операций. ${ }^{1}$ Эта стратегия применялась в течение прошедших лет, и Альянс задействовал новые программы и механизмы (например Концепция оперативных способностей (КОС), План действий по членству (ПДЧ) и Индивидуальный план действий по партнерству (ИПдП)) для более тесного и углубленного сотрудничества с его партнерами. Целью всех партнерств НАТО, как это заявлено во всех трех концепциях, принятых после Холодной войны, является совместное гарантирование безопасности. В текущей Стратегической концепции (2010) тремя основными задачами НАТО являются коллективная оборона, менеджмент кризисов и совместная безопасность.

1 Partnership for Peace Planning and Review Process, NATO Topics, last updated November 5, 2014, https://www.nato.int/cps/en/natohq/topics_68277.htm. 
Из этих задач совместная безопасность сильнее всего связана с партнерствами. Совместная безопасность является широкой задачей, состоящей из многочисленных элементов. В основном, она состоит из трех компонентов: укрепление партнерства, содействие контролю над вооружениями, нераспространению и разоружению и содействие потенциальным новым государствам в их подготовке к членству в НАТО. Важным подэлементом как укрепления партнерств, так и подготовки новых стран к членству является оперативная совместимость. ${ }^{2}$ Вкратце, в связи с новыми миссиями НАТО и участием сил Альянса на оперативных театрах имеет место драматическое смещение от ситуации, когда одна страна воюет сама, к коалициям, при которых многонациональные формирования, вплоть до уровня взвода, работают совместно.

\section{Стратегия обеспечения развития оперативной совместимости}

В настоящее время мир погружен в гораздо более сложную среду безопасности, чем та, которая имела место несколько десятилетий назад. Поэтому, в качестве эпицентра глобальной безопасности НАТО нужно быть на уровне вызовов, с которыми сталкиваются его члены и страны-партнеры. Реализация большой стратегии Альянса требует постоянного улучшения военной эффективности. В этом плане, оперативная совместимость является sine qua non [обязательным] условием для успеха операции/миссии в коалиционных военных действиях. На Чикагском саммите в 2012 году Альянс запустил некоторые новые программы, например, "Умная оборона» (УО) и Инициатива связанных сил (ИСС). Причиной инициирования этих программ снова было стремление к большей оперативной совместимости и когерентности. ${ }^{3}$ На саммите была принята декларация, подчеркивающая важность оперативной совместимости: «Последний опыт операций Альянса так же показывает, что способность сил НАТО действовать совместно без препятствий и быстро является критически важной для успеха. Поэтому, мы будем гарантировать, что силы Альянса будут оставаться хорошо связанными путем расширенного обучения, практической подготовки и учений». ${ }^{4} \mathrm{Ha}$ данном этапе, важно обратить внимание на многочисленные последствия, которые

2 Stephen J. Maranian, "NATO interoperability: Sustaining Trust and Capacity within the Alliance," Research Paper 115 (Rome: Research Division, NATO Defense College, June 2015), https://www.files.ethz.ch/isn/192707/rp_115.pdf.

3 What is Transformation? An Introduction to Allied Command Transformation, with foreword by Lieutenant General Phil Jones, Chief of Staff (Norfolk, Allied Command Transformation, January 2015), http://www.ieee.es/Galerias/fichero/OtrasPublica ciones/Internacional/2015/NATO_Introduction_AlliedCommand_Transformation_Ja n2015.pdf.

4 Marcel-Petru Ivut and Florian Ianoşiu Hangan, "Interoperability between NATO and Partner States in the post-ISAF Period. Present and Perspectives," Romanian Military Thinking 11, no. 4 (October-December 2015): 116-124, http://smap.mapn.ro/gmr/ Engleza/Arhiva_pdf/2015/revista_4.pdf. 
может иметь отсутствие оперативной совместимости. Во-первых, оно может подвергнуть опасности успешное выполнение оперативных миссий. Вовторых, оно может иметь большое отрицательное воздействие на ресурсы и логистику, поскольку оно затрудняет или даже делает невозможным обмен резервными частями, боеприпасами и горючим и, следовательно, оказывает влияние на эффективность сил в целом. В некоторых сферах оперативная несовместимость может иметь драматические последствия, например, огонь по своим или ненужные человеческие потери. Доказано, что улучшение оперативной совместимости увеличивает эффективность операций НАТО и сохраняет жизни и ресурсы. ${ }^{5}$ Поэтому, в интересах всех осуществлять сотрудничество и инвестировать в обеспечение самого высокого уровня оперативной совместимости и взаимодействия. В декларации саммита в Чикаго четыре или пять ссылок на оперативную совместимость касаются партнерств со странами вне Альянса: Грузии, Украины, стран Средиземноморского диалога и вообще партнеров, присутствующих на саммите. ${ }^{6}$ Такое отношение, в свою очередь, стимулирует политику «открытых дверей» и расширения НАТО. В апреле 2013 года, когда генерал Фил Бридлав принял Европейское командование вооруженных сил США, на слушаниях по его утверждению, ему был задан вопрос о наиболее важных уроках 10 лет операций НАТО в Афганистане. На первом месте в его списке была возросшая способность США и союзных войск буквально воевать и действовать плечом к плечу: «Прежде всего, НАТО в целом и некоторые из его партнеров достигли гораздо более высокой оперативной совместимости». Далее, генерал Бридлав сказал, что утрата этой оперативной совместимости была одной из ключевых тревог при обдумывании как будет развиваться Североатлантический Альянс после Афганистана. ${ }^{7}$

На саммите в Уэльсе в 2014 году Альянс актуализировал концепцию сил реагирования НАТО (СРН), которая была создана в 2002 году на саммите в Праге. Но ее значение стало по-настоящему очевидным, только когда Россия оккупировала Крым в начале 2014 года. Силы реагирования являются технологически передовыми, гибкими, развертываемыми, оперативно совместимыми и находящимися в постоянной готовности силами, которые включают сухопутный, морской и воздушный элемент, которые находятся в наличности всегда, когда в них есть необходимость. Они задуманы как средство для трансформации военных структур и военных способностей

5 Florian Ciocan, "Perspectives on Interoperability Integration within NATO Defense Planning Process," Journal of Defense Resources Management 2, no. 2 (2011), 53-66, http://www.jodrm.eu/issues/volume2_issue2/06_ciocan.pdf.

6 Maranian, "NATO interoperability."

7 John R. Deni, "Whose Responsibility is Interoperability?" Small Wars Journal, June 26, 2013, http://smallwarsjournal.com/jrnl/art/whose-responsibility-is-interoperability. 
стран-членов и стран-партнеров. ${ }^{8}$ Рассмотрение последних трех деклараций встреч глав стран и правительств НАТО показывает, что оперативная совместимость упоминается шестнадцать раз. Декларация саммита в Уэльсе ${ }^{9}$ придает этой концепции гораздо большее значение, чем декларации саммитов в Чикаго ${ }^{10}$ и в Варшаве, ${ }^{11}$ где она упоминается только пять и тринадцать раз, соответственно. Поэтому можно утверждать, что саммит в Уэльсе в 2014 году положил основу для улучшения оперативной совместимости между НАТО и странами-партнерами, инициировав программы и механизмы, значение которых нельзя переоценить.

К 2014 году, когда НАТО готовилось к завершению своей операции в Афганистане, союзные вооруженные силы совместно участвовали в боевых и постконфликтных сухопутных, морских и воздушных операциях более 20 лет. ${ }^{12}$ Чтобы применять эту стратегию, всем игрокам нужно думать и действовать согласованно. Здесь речь идет о получении и сохранении конкурентных преимуществ, о процессе, который включает заполнение пробелов и, в частности, пробелов, созданием которых в будущем угрожает изменяющаяся среда. Последние нарушающие стабильность события в мире и в евроатлантическом регионе подтверждают оценки НАТО, что будущая среда безопасности будет неустойчивой, сложной и неопределенной. Политическая адекватность Альянса и военная эффективность его сил будет сталкиваться с вызовами в результате сочетания этой сильно динамичной, взаимосвязанной и неоднозначной оперативной среды с периодом продолжающихся бюджетных ограничений. ${ }^{13}$ В этом плане постоянное усовершенствование военных структур и способностей Азербайджанской республики имеет наивысшее значение, поскольку оно определяет эффективность и оперативную совместимость вооруженных сил Азербайджана с вооруженными силами Альянса.

8 Juha Pyykönen, "Partners of NATO: How similar are Finland and Sweden within NATO cooperation?" FIIA Report 48 (Helsinki: Finish Institute of International Affairs ,2016), https://www.fiia.fi/en/publication/nordic-partners-of-nato.

9 Wales Summit Declaration, Issued by the Heads of State and Government participating in the meeting of the North Atlantic Council in Wales, NATO e-Library, Official Texts, September 5, 2014, www.nato.int/cps/en/natohq/official_texts_112964.htm.

10 Chicago Summit Declaration, Issued by the Heads of State and Government participating in the meeting of the North Atlantic Council in Chicago on 20 Mау 2012, последнее обновление 1 августа 2012, www.nato.int/cps/en/natohq/official_texts_87593.htm.

11 Warsaw Summit Communiqué, Issued by the Heads of State and Government participating in the meeting of the North Atlantic Council in Warsaw 8-9 July 2016, последнее обновление 29 марта 2017, https://www.nato.int/cps/en/natohq/ official_texts_133169.htm.

12 Charles Barry, "Building Future Transatlantic Interoperability Around a Robust NATO Response Force," Transatlantic Current 7 (Washington, D.C.: National Defense University, Institute for National Strategic Studies, October 2012), цитата на с. 1.

13 "What is Transformation?" c. 3. 
Глоссарий терминов и дефиниций НАТО определяет оперативную совместимость как «способность сил двух или более государств проводить эффективно совместную подготовку, учения и операции во исполнение назначенных миссий и задач». ${ }^{14}$ Политика по оперативной совместимости определяет это понятие как способность действовать вместе согласованно, эффективно и результативно для осуществления тактических, оперативных и стратегических целей. Конкретнее, оперативная совместимость позволяет силам, формированиям или системам функционировать совместно и использовать общие доктрины и процедуры, а также инфраструктуру и базы друг друга, и быть в состоянии осуществлять коммуникацию друг с другом. Оперативная совместимость уменьшает дублирование, позволяет общее использование ресурсов и осуществляет синергию среди 28 союзников, и, когда это возможно, со странами-партнерами. ${ }^{15}$ Поэтому, оперативная совместимость имеет место на разных уровнях - стратегическом, оперативном и тактическом, а также на технологическом. Из-за этих разных уровней и множества измерений оперативную совместимость можно рассматривать, исходя из наиболее широко наличного определения: «Способность систем, формирований или сил предоставлять услуги и принимать услуги от других систем, формирований или сил и использовать эти обмениваемые услуги для совместного эффективного проведения операций». ${ }^{16}$

На стратегическом уровне оперативная совместимость является одним из наиболее существенных факторов, способствующих созданию коалиции сил, и таким образом, демонстрации членами коалиции желания действовать совместно против общих угроз всегда, когда это необходимо. На этом уровне оперативная совместимость сосредоточена на гармонизации глобальных концепций стратегий, доктрин и структур сил стран-членов. На оперативном и тактическом уровнях оперативная совместимость касается, главным образом, того, как вопросы оперативной совместимости, которые были согласованы на политическом и стратегическом уровнях, работают совместно для поддержки союзных или партнерских государств или членов коалиции в осуществлении менеджмента кризисов, создании среды для достижения набора целей и обеспечения победы в войне. На оперативном и на тактическом уровнях оперативная совместимость зависит от синхронизации между союзными и партнерскими силами. В общем и в целом, польза от обеспечения совместимости на оперативном и тактическом уровнях видна при взаимном обмене коалиционными силами и формированиями/

14 Ivut and Hangan, "Interoperability between NATO and partner states."

15 “Partnership Interoperability Initiative," NATO Tорісs, последнее обновление 7 июня 2017, https://www.nato.int/cps/en/natohq/topics_132726.htm.

16 "A Broad Definition of Interoperability," Chapter 2 in Myron Hura, Gary W. McLeod, Eric V. Larson, James Schneider, Dan Gonzales, Daniel M. Norton, Jody Jacobs, Kevin M. O'Connell, William Little, Richard Mesic, and Lewis Jamison, Interoperability: A Continuing Challenge in Coalition Air Operations (Santa Monica, CA: RAND Corporation, 2000), 7-15, www.rand.org/pubs/monograph_reports/MR1235.html. 
подразделениями. ${ }^{17}$ На технологическом уровне преимущества оперативной совместимости проистекают, на первом месте, из их влияния на оперативный и тактический уровень в плане усиления взаимозаменяемости и гибкости. Этот уровень касается «компьютеров и коммуникаций, но также включает технические способности систем, и проистекающая из них совместимость или несовместимость между системами (аппаратной части и программного обеспечения) и данными партнеров по коалиции». ${ }^{18}$ Поэтому, можно считать, что плюсами оперативной совместимости на всех уровнях являются развертываемость, гибкость, устойчивость, мобильность и живучесть. Данное описание показывает, что оперативная совместимость является одним из главных требований для эффективных операций.

Для того, чтобы пролить свет на все уровни оперативной совместимости, можно в качестве примера рассмотреть способ возможного ведения воздушной кампании (как показано на фигуре 1). В этом примере стратегический уровень отвечает за воздушно-космическую политику и создает воздушно-космические структуры. Уровень кампании занимается планированием и ведением операций, а также планированием строительства сил в соответствие с доктринами НАТО. Главным элементом на этом уровне является политическая готовность к сотрудничеству. Оперативная совместимость на оперативном уровне имеет место, когда стратегическая и тактическая совместимость сочетаются для управления кризисными ситуациями. Распределение воздушного пространства осуществляется на тактическом уровне. Воздушно-космические структуры, определенные на этом уровне, распределяются среди заинтересованных «держателей» воздушного пространства. Технологический уровень касается технических возможностей систем и данных коалиции партнеров реагировать схожим образом на конкретные ситуации.

Обеспечение оперативной совместимости на всех уровнях является постоянной необходимостью. В государствах-членах НАТО это достигается применением договоренных стандартов. Что касается стран-партнеров, достижение высокого уровня оперативной совместимости является ключевым фактором с учетом совместного участия в операциях/миссиях под руководством НАТО. ${ }^{19}$ Тогда как страны-члены НАТО принимают участие в этом процессе на всех уровнях, страны-партнеры не участвуют в нем на стратегическом уровне. Между тем, Альянс развивает партнерства на разных уровнях, и странам-партнерам принадлежит право выбирать уровень, на котором они желает принимать участие, чтобы укреплять свой мир и стабильность. Поскольку Азербайджан не артикулировал желание на полное членство в НАТО, выбор конкретного способа достижения оперативной совместимости

17 Ivut and Hangan, "Interoperability between NATO and Partner States."

18 "A Broad Definition of Interoperability," c. 13.

19 Ivut and Hangan, "Interoperability between NATO and Partner States." 


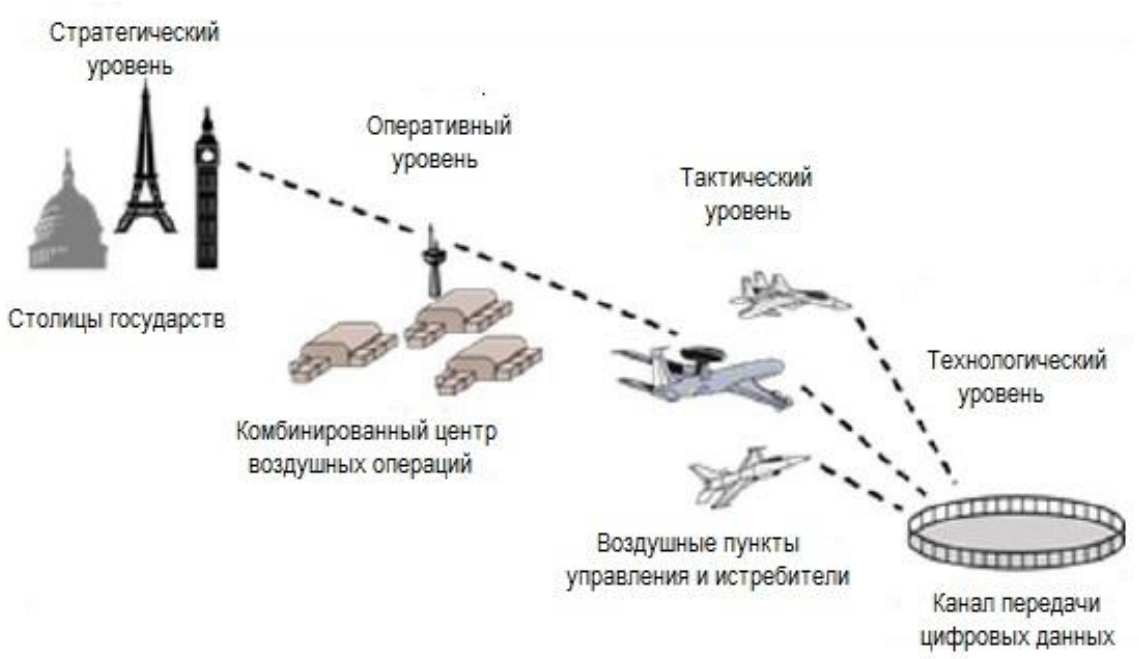

Фигура 1: Оперативная совместимость на четырех уровнях - случай воздушной кампании. 20

с военной точки зрения означает получить какие-то пользы от использования инструментов и механизмов, касающихся образования и практической подготовки, которые Альянс задействовал в прошедшие годы. Действительно, эти инструменты являются неоценимым средством для улучшения оперативной совместимости и способностей на всех уровнях. Используя эти возможности, вооруженные силы некоторых стран-партнеров (например, Австрии, Финляндии и Швеции) добились высокого уровня оперативной совместимости в результате многих лет участия в совместной подготовке и совместных учениях на первых трех уровнях. Оперативная совместимость не является обязательно политическим решением, чаще всего это технический вопрос. Поэтому нет никаких препятствий для того, чтобы вооруженные силы Азербайджана стали полностью оперативно совместимыми с силами НАТО.

Оперативная совместимость не обязательно означает, что государствочлен или государство-партнер должно иметь или должно покупать общее военное оборудование. В той же степени, или даже в большей, скорее речь идет о командной работе людей, чем о совместимости машин и процессов. Особенно важно располагать способностью использовать существующее оборудование, предоставляя друг другу сооружения, и таким образом быть в состоянии взаимодействовать, поддерживать связь, коммуникировать и

20 "A Broad Definition of Interoperability," c. 9. 
обмениваться информацией и услугами с использованием схожего оборудования из арсенала других государств. ${ }^{21}$ Здесь надо упомянуть, что вооруженные силы Азербайджана сделали гигантский шаг, используя концепцию Штабного элемента партнерства НАТО (ШЭП) и его Программу развития образования в сфере обороны (ПРОО). Концепция ШЭП дает возможность Азербайджану посылать своих офицеров в разные штабы и командования НАТО для приобретения опыта и знаний путем работы плечом к плечу с союзниками в этих штабах и командованиях. Азербайджан эффективно использует этот инструмент, и с 2002 года отправил более 20 офицеров на разные ШЭП должности, что делает его одним из самих больших среди стран ПрМ участников партнеров штабной деятельности. ${ }^{22}$ После завершения их миссий эти офицеры назначаются на разные руководящие должности, где они способствуют развитию отношений между НАТО и Азербайджаном. Идентифицировав свои потребности в военной сфере, Азербайджан начал широко использовать экспертные консультации НАТО путем применения программы ПРОО для того, чтобы модернизовать свою систему военного образования с целью стать интеллектуально оперативно совместимым с Альянсом.

С учетом вышеупомянутых аспектов можно прийти к заключению, что оперативная совместимость охватывает следующие области ${ }^{23}$ :

1. Способность сил из разных стран эффективно работать совместно;

2. Эффективность совместной организационной структуры вооруженных сил;

3. Степень схожести технических способностей сил из разных государств.

Согласно плану действий, одобренному министрами обороны НАТО, оперативная совместимость имеет три измерения ${ }^{24}$ :

1. Техническое (аппараты и системы)

2. Процедурное (доктрины и процедуры)

3. Человеческое (язык, терминология, подготовка).

С другой стороны, механизмами, которые обеспечивают достижение оперативной совместимости, являются: эффективное применение договоренных союзных стандартов (STANAG), доктрин и тактик: участие в учениях НАТО и в многонациональных учениях; применение политики НАТО в отно-

21 Ivut and Hangan, "Interoperability between NATO and Partner States."

22 Azerbaijan - NATO partnership (Brussels: Mission of Azerbaijan to NATO, 2014), http://nato-pfp.mfa.gov.az/files/file/broch_AZE-OTAN_LR.pdf.

23 "A Broad Definition of Interoperability."

24 "Interoperability: Connecting NATO Forces," NATO Topics, последнее обновление 6 июня 2017, https://www.nato.int/cps/ic/natohq/topics_84112.htm. 
шение извлеченных уроков и проведение демонстраций и испытаний. Согласно Стратегической концепции НАТО 2010, партнерство с третьими странами «может дать конкретный вклад в повышение международной безопасности, в защиту ценностей, на которых основывается Альянс, в операции НАТО и в подготовку заинтересованных стран к членству в НАТО». ${ }^{25}$

Оперативная совместимость в коалиционной войне является стержнем оборонной политики и военной доктрины США. Стратегическое руководство по обороне от января 2012 года, самый последний стратегический документ министерства обороны (МО), на своих восьми коротких страницах шесть раз подчеркивает значение союзников и партнеров. Последняя версия краеугольной доктринальной публикации вооруженных сил на 200 страницах ссылается на оперативную совместимость 87 раз. ${ }^{26}$

На саммите НАТО в Чикаго в 2012 году НАТО выразило готовность и далее укреплять и углублять свои партнерства. Это было еще раз подтверждено на саммите в Уэльсе, когда была задействована Инициатива партнерской оперативной совместимости (ИПОС) для поддержания и углубления уровня оперативной совместимости, который уже был достигнут с партнерами в ходе операций и миссий под руководством НАТО в течение последних десятилетий. ИПОС еще раз подчеркнула значение оперативной совместимости для всех партнерств и дала новые средства для углубления сотрудничества с теми партнерами, которые выразили желание стать оперативно совместимыми с НАТО. Как подчеркнул заместитель Генерального секретаря НАТО, Александр Вершбоу: «Это первый учрежденный консультативный форум, посвященный оперативной совместимости, и к настоящему времени самая большая возможность для сотрудничества и диалога для тех, кто желает быть партнером с повышенными возможностями». ${ }^{27}$ В ИПОС включена «Платформа по оперативной совместимости» для 25 избранных партнеров и индивидуализированная программа «Повышенные возможности» для углубленного сотрудничества с пятью конкретными партнерами (Австралия, Финляндия, Грузия, Иордания и Швеция). ${ }^{28}$ Эта инициатива предоставляет увеличенные возможности для сотрудничества с партнерами для противодействия угрозам безопасности через:

1. Интегрирование всех существующих механизмов и программ по оперативной совместимости;

2. Поддержку партнеров, которые желают стать оперативно совместимыми;

3. Предоставление увеличенных возможностей партнерам, которые дают существенный вклад в мероприятия Альянса; и

\footnotetext{
25 Ivut and Hangan, "Interoperability between NATO and Partner States."

26 Barry, "Building Future Transatlantic Interoperability."

27 "Partnership Interoperability Initiative."

28 "Partnership Interoperability Initiative."
} 
4. Создание, поддерживание, диверсифицирование и расширение общих сил и способностей, принадлежащих странам-партнерам, которые сертифицированы и готовы участвовать в будущих операциях НАТО или в СРН. ${ }^{29}$

Второй инициативой, одобренной саммитом в Уэльсе для укрепления готовности НАТО к выполнению основной задачи обеспечения кооперативной безопасности, является Инициатива по строительству способностей для обороны и связанных с обороной способности по обеспечению безопасности (ССО). Эта инициатива направлена на оказание помощи партнерам для обеспечения их собственной безопасности путем укрепления оборонных и связанных с безопасностью способностей. ${ }^{30}$ В этом плане Процесс планирования и мониторинга в рамках Партнерства ради мира, Концепция оперативных способностей и Партнерство в сфере военной подготовки и военных учений являются главными инструментами для развития оперативной совместимости и способностей сил стран-партнеров. Недавно Альянс разработал Индивидуализированную концепцию дорожной карты, которая должна упростить существующие партнерские программы и улучшить сотрудничество путем повышения ситуативной информированности и доверия. Были инициированы пилотные проекты, которые касаются разных аспектов киберобороны, совместно с Финляндией, Грузией и Иорданией. Другой моделью того, как НАТО и его коалиционные партнеры работали совместно для улучшения оперативной совместимости и обмена информацией в ходе операций, учений и мероприятиях по подготовке, является Федерированная информационная сеть для миссий. Эта рамка включает политику, процессы, процедуры, стандарты и физические компоненты, в том числе стационарные и развертываемые сети, услуги и поддерживающая инфраструктура. Партнеры будут принимать участие в работе по раннему обнаружению, предотвращению и анализу киберугроз. ${ }^{31}$

Вооруженные силы НАТО достигли высокого уровня оперативной совместимости благодаря десятилетиям совместного планирования, проведения подготовки и учений. Страны-члены осуществляли оперативную совместимость на практике и развивали ее в ходе совместных операций и миссий. Эти операции позволили и странам-партнерам повысить свою оперативную

29 Ivut and Hangan, "Interoperability between NATO and Partner States."

30 "Partnership Tools," NATO Topics, last updated June 24, 2016, www.nato.int/ cps/en/natohq/topics_80925.htm.

31 Piret Pernik and Tomas Jermalavičius, "Resilience as Part of NATO's Strategy: Deterrence by Denial and Cyber Defense," in Forward Resilience: Protecting Society in an Interconnected World, ed. Daniel S. Hamilton (Washington, D.C.: Center for Transatlantic Relations, Paul H. Nitze School of Advanced International Studies, Johns Hopkins University, 2016), 99-112, https://archive.transatlanticrelations.org/publication/ forward-resilience-protecting-society-interconnected-world/. 
совместимость с Альянсом. ${ }^{32}$ Лучшим примером этого являются Международные силы содействия безопасности как в смысле преимуществ, проистекающих из достижения высокого уровня оперативной совместимости между НАТО и странами-партнерами, так и в смысле необходимости сохранять достигнутый уровень. ${ }^{33}$ Если сохранение, и даже развитие, достигнутого уровня оперативной совместимости со странами-партнерами является приоритетом для НАТО, то тогда желание Азербайджана добиться гораздо более углубленного сотрудничества с Альянсом является реалистической целью.

\section{Заключение}

Чтобы быть оперативно совместимым с силами НАТО, от данного государства требуется, чтобы оно располагало квалифицированными военными способностями. Азербайджан развивает свои военные способности с того момента, как он добился независимости от СССР. Азербайджан является полным энтузиазма партнером НАТО. Однако, для повышения его оперативной совместимости с НАТО надо сделать еще многое. Азербайджану нужно пойти дальше достигнутой минимальной оперативной совместимости и добиться более высокого уровня интеграции. Учитывая все четыре уровня оперативной совместимости, введенные в этой статье, Азербайджан, предположительно, активно принимает участие в первых трех уровнях (технологическом, тактическом и оперативном уровне). Чтобы реализовать все эти цели, Азербайджану будет необходимо усовершенствовать свои национальные способности для проведения операций в ответ на кризисы и, таким образом, стать эффективным, активным и надежным партнером в случае кризиса. Поэтому учения и подготовка с повышенными требованиями приветствуются Азербайджаном, поскольку многонациональные учения эффективным образом проверяют достигнутый уровень оперативной совместимости. Основной вывод здесь состоит в том, что чем больше данный партнер инвестирует в сотрудничество, тем больше выгод он получает от него. ППОП остается одним из наиболее эффективных для Азербайджана механизмов в сфере обороны и планирования сил. Широко следует использовать Концепцию оперативных способностей для обеспечения требуемого уровня оперативной совместимости вооруженных сил.

Чтобы повысить оперативную совместимость с западными силами, Азербайджан может воспользоваться советами НАТО в таких областях, как строительство институтов в сфере обороны, кибероборона, логистика и стандартизация. НАТО, в свою очередь, могло бы создать более эффективные программы помощи и участия для Азербайджана, учитывая его уязвимость в плане агрессии со стороны соседей. ПРОО является неоценимым

32 "Interoperability: Connecting NATO Forces."

33 Ivut and Hangan, "Interoperability between NATO and Partner States." 
инструментом для развития образовательных институций в секторе обороны и для обеспечения интеллектуальной оперативной совместимости личного состава азербайджанских вооруженных сил с персоналом вооруженных сил НАТО.

Как часть «Платформы по оперативной совместимости», Азербайджан осознал важность совместной работы с НАТО и может иметь выгоды от более индивидуализированных отношений, например от "Усовершенствованных возможностей» для поддержания оптимального уровня оперативной совместимости. Таким образом, Альянс может создать дополнительные индивидуализированные программы, базирующиеся на индивидуальных потребностях Азербайджана. В дополнение к вышеупомянутым программам, Азербайджан может просить помощи в виде пакета строительства оборонных и связанных с обороной способностей по обеспечению безопасности через образование и подготовку. Силы реагирования НАТО являются центральной платформой для поддержания оперативной совместимости, и Азербайджан мог бы иметь выгоду от концепции инициативы Связанных сил для усовершенствования подготовки своих войск и, с использованием современной технологии, для облегчения оперативной совместимости и интеграции требуемых способностей. Также, добиваясь минимального уровня, требуемого оценщиками КОС для потенциальных операций, Азербайджан мог бы участвовать в учениях СРН с другими выделенными силами, поскольку это является наиболее очевидным инструментом для сертификации совместимых способностей между НАТО и Азербайджаном. И последнее, важно подчеркнуть, что изучение иностранного языка является предварительным условием для всего комплекса деятельностей, связанных с оперативной совместимостью. В первую очередь это, конечно, английский язык в качестве языка интегрированной военной структуры НАТО. Поэтому, под эгидой Военной академии с целью изучения разных иностранных языков личным составом Вооруженных сил функционирует Центр иностранного языка и партнерства. Позволяя военному персоналу Азербайджана осуществлять коммуникацию на английском языке на приличном уровне (STANAG 2-3), он дает ему возможность изучать тактику НАTO в военной сфере.

\section{Об авторах}

Профессор Эльман Насиров, доктор политологии и директор Института политических исследований Академии публичной администрации при президенте Азербайджана. Он также член парламента Республики Азербайджан.

Хаяль Искандаров является начальником редакторского отдела Академии вооруженных сил Республики Азербайджан. У него степень магистра военных наук, и в настоящее время он учится в аспирантуре в области военных наук и национальной безопасности. E-mail: xayal1333@gmail.com. 